\title{
La ciudad de Argel, espacio de ilusión y desencanto en dos escritoras argelinas: Maïssa Bey y Assia Djebar
}

\author{
Jean-Pierre CASTELLANI \\ Universidad François Rabelais de Tours (Francia) \\ jpcastellani@wanadoo.fr
}

Recibido: $04 / 02 / 2013$

Modificado: 08/04/2013

Aceptado: 30/04/2013

\section{Resumen}

La ciudad de Argel constituye un caso ejemplar para estudiar la representación que hacen de ella las voces femeninas de la narrativa argelina que han vivido en ese espacio tan singular, a la vez occidental y oriental, en los últimos años de la colonización y en los primeros años de la independencia de Argelia, a partir de 1962. La ciudad es el marco de historias personales relacionadas con la condición de la mujer, cuya relación con la ciudad ilustra la evolución que se produce desde la ilusión al principio de las independencias hasta el desencanto actual.

Palabras clave: espacio, Argel, occidental, oriental, representación, mujer.

Title: The city of Algiers, space of illusion and disillusionment in two Algerian writers: Maïssa Bey and Assia Djebar

\section{Abstract}

The city of Algiers is a model case for studying its representation in the narrative voices of Algerian women who have lived in this area so unique, both West and East, in recent years of colonization and early years of the independence of Algeria from 1962. The city is the framework of personal stories related to the condition of women, whose relationship with the city is interesting from the initial illusion to the current disenchantment.

Keywords: space, Algiers, westerner, oriental, representation.

\section{Índice}

1. Introducción

2. Representaciones literarias de Argel en textos escritos por mujeres argelinas

2.1. Maïssa Bey

2.1.1. Biografía

2.1.2. Producción

2.1.3. Bleu, blanc, vert (2003)

2.2. Assia Djebar

2.2.1. Biografía/Obra

2.2.2. Nulle part dans la maison de mon père (2007)

3. Conclusión 


\section{Introducción}

El título del libro recientemente coordinado por Beida Chikhi y Anne Douaire-Banny, Villes, vies, visions: Les villes, propriétés de l'écrivain. Espaces littéraires (2012), lo dice todo en cuanto al tema de la relación entre escritores y ciudades. Se trata de las actas de un coloquio internacional organizado por la Universidad de París-Sorbona en la ciudad de Abu Dhabi, en 2009. En esa ciudad moderna sin tradición, y de momento sin la mirada de escritores que la visiten, se han estudiado ciudades como Florencia, Estambul, Roma, Barcelona, Zanzíbar, Buenos Aires, París, Bagdad, etc. La conclusión del encuentro fue, como indica el mismo título del libro, que las ciudades son propiedad del escritor, a la vez que el escritor es propiedad de las ciudades: "La ville appartient à un lieu qui lui préexiste, et ce lieu est déjà habité. Le génie du lieu nous raconte les mêmes histoires, sous des formes différentes" (Chikhi y Douaire-Banny 2012: 268).

En esta investigación colectiva dedicada a la problemática de las voces de mujer en la ciudad, escojo esta temática de la mujer argelina frente a la ciudad de Argel por muchos motivos: en primer lugar, es indudable que Argel forma parte de esas ciudades mediterráneas míticas, como Marrakech o Tánger. Es una ciudadtexto, en el sentido que le daba al concepto Michel Butor. Por otra parte, es una ciudad que ha conocido un crecimiento indudable con la colonización francesa y que luego ha sido el centro de uno de los episodios más sangrientos de la Guerra de Independencia. En ella se produjo la Batalla de Argel. Su mítica Alcazaba rebelde fue testigo de los atentados de la guerrilla del FLN en la ciudad europea en 1957, duramente reprimidos por el ejército francés, luego de los primeros años de la Independencia (1962), para terminar contemplando una nueva guerra con los islamistas (1991-2000). Con esta auténtica guerra civil irrumpe un terrorismo sangriento en los mismos lugares de la ciudad, como si hubiera una fatalidad de muerte en ella.

Así que lo que hace la originalidad de la ciudad es su carácter doble y la mezcla de identidades que la sigue definiendo: la realidad argelina de hoy, por un lado, y esa sombra de la antigua colonia francesa, por otro. Argel encarna lo que Paul Siblot llama "la ciudad bífida de la sociedad colonial" (Siblot 1992: 44). Provoca la fantasía por todos esos motivos: sueños de aquellos europeos que tuvieron que dejarla, ilusión de los argelinos que descubren la parte europea de modo inesperado, para luego sentir el desencanto por la evolución política del país. Durante mucho tiempo objeto de seducción exótico para los viajeros extranjeros -como lo prueba el famoso cuadro de Eugène Delacroix Mujeres de Argel en un interior (1834)-, Argel destaca ahora en su dualidad, por su mezcla singular de un mundo oriental y de un mundo occidental, por la superposición de estilos que en ella conviven. Es a la vez una ciudad mediterránea y europea. Es una ciudad palimpsesto en el sentido exacto de la palabra: 
manuscrito que todavía conserva huellas de otra escritura anterior en la misma superficie, pero borrada expresamente para dar lugar a la que ahora existe. En arqueología se llama palimpsesto, por ejemplo, a un yacimiento que presenta una mezcla de estratos. Es evidente que una ciudad suele tener estratos que dan lugar a ciudades superpuestas. El ensayista francés Olivier Mongin ensancha la noción de palimpsesto a la ciudad al hablar de "ciudad palimpsesto" en su trabajo La condition urbaine. La ville à l'heure de la mondialisation (2005).

En el caso de Argel, además de esa superposición que comparte con todas las ciudades del Mediterráneo, observamos pues la dualidad de ser ciudad europea, es decir occidental, y de ser también ciudad musulmana, o sea oriental.

Cuentan asimismo en la elección del tema motivos personales relativos a mi propia biografía: por haber vivido mi infancia en Argel, por haber luego conocido el exilio, por regresar a ella periódicamente por motivos de trabajo desde 2003, en una especie de reencuentro singular. En un coloquio anterior había estudiado las miradas cruzadas sobre Argel por parte de escritores con diversos puntos de vista: la perspectiva lúcida de autores que han vivido en Argelia como Albert Camus, que la colocaba entre las "ciudades sin pasado" (Camus 1954); la perspectiva nostálgica de intelectuales europeos desterrados, que abandonaron la ciudad en 1962 y que siguen queriéndola profundamente, como Alain Vircondelet, quien vive un re-encuentro con la ciudad de esos años, una ciudad perdida definitivamente, en la cual no ha dejado de pensar (Vircondelet 1982); el punto de vista muy crítico de novelistas argelinos como Tahar Djaout ${ }^{1}$, que la ve como una especie de paisaje después de la batalla, de infierno, de fin del mundo, poblado de fantasmas errantes (Djaout 1999), o como Rachid Boudjedra, que la percibe como una inocente mujer violentada, una víctima de las locuras de la Historia (Boudjedra 1991).

Dan de ella la imagen de un universo de destrucción y podredumbre, más cercano al universo de Beckett que al costumbrismo realista, con una desrealización que desemboca, en definitiva, en un hiperrealismo caótico y en la visión de una ciudad presuntuosa, histérica y burlesca. En esos casos, Argel se vuelve una metáfora de la Argelia de hoy y del caos que a menudo la caracteriza. Pasamos así en estas novelas de un nivel realista a un nivel simbólico, de una ciudad visible a una ciudad invisible.

Mi objetivo consiste hoy en reflexionar sobre la relación entre las escritoras argelinas y la ciudad de Argel, destacando la diferencia

1 Tahar Djaout, escritor, poeta y periodista fue una de las víctimas del terrorismo integrista en 1993. 
del tratamiento que hacen ellas de la urbe respecto al que hacen los autores masculinos, para ver en qué medida sus voces son distintas. Desde esta perspectiva, resulta muy interesante plantear la representación literaria de la ciudad en obras escritas por dos novelistas argelinas cuya biografía abarca el final de la Guerra de Independencia, con recuerdos precisos y dramáticos que se corresponden con su niñez o su adolescencia, y los primeros años de la Argelia libre, que coinciden con su llegada a Argel como estudiantes, o sea un encuentro biográfico, sociológico y político con la ciudad. Me refiero a Maïssa Bey, con Bleu blanc vert (2006), y a Assia Djebar, con Nulle part dans la maison de mon père (2007).

Vamos a ver que Argel es, en estos dos casos, el marco natural de historias personales, para acabar siendo la metáfora de la historia colectiva, ya sea de los europeos, ya sea de los argelinos.

\section{Representaciones literarias de Argel en textos escritos por mujeres argelinas}

\subsection{Maïssa Bey}

\subsubsection{Biografía}

Maïssa Bey, pseudónimo de Samia Benameur, nació en 1950, en Ksar El Boukari (Argelia), pueblo de la región de Medea, no muy lejos de Argel. Nieta de un rico terrateniente analfabeto de las Altas Mesetas, aprende el francés con su padre, maestro nacionalista partidario de la Independencia de Argelia. Alistado en la guerrilla del FLN, fue secuestrado en 1957 por el ejército francés y torturado. La niña Maissa no volvió a verle.

Los libros y la literatura francesa -el francés es su idioma paterno- han permitido a Maissa Bey refugiarse en un mundo que la protegía de esa pregunta tan dura: ¿cómo entender el secuestro y el asesinato de un padre por parte de unos franceses cuya literatura, cultura e idioma ella adoraba? Durante su infancia estuvo rodeada de libros que devoraba en la biblioteca, presa de bulimia lectora desde la edad de cinco años. Naturalmente se dedicó a estudios de Letras en la Universidad y ha ejercido el oficio de profesora de francés y de consejera pedagógica en Sidi-Bel-Abbès, donde vive actualmente. Es madre de cuatro hijos. Siempre ha permanecido en Argelia viviendo y trabajando, incluso durante la década negra. Es cofundadora de la asociación de mujeres argelinas "Palabras y escritura" y colabora en la revista Estrellas de tinta, revista de mujeres en el Mediterráneo.

Entre el nacimiento de Maïssa Bey y sus primeros textos, Argelia conoció una larga y dolorosa guerra de Independencia que provocó la muerte de su padre en los combates por la liberación, y luego, una violenta guerra civil en los años 90. Maïssa Bey, siendo una niña durante la Guerra de Independencia, vivió como adulta y fue testigo de la rebelión sangrienta de los islamistas desde 1990 hasta 2000. Fue a partir de entonces cuando tomó la palabra como 
escritora, con unas obras consideradas valientes, heterodoxas y originales. Pasó de una Argelia colonial a una Argelia descolonizada, de una guerra de independencia a una guerra civil, en ambos casos, con la experiencia de enfrentamientos sangrientos, dolorosos y traumáticos.

Maïssa Bey reivindicó siempre su conciencia argelina y su compromiso ciudadano, centrales en ella, y manifestó una presencia apasionada, masiva, obsesiva de esta misma Argelia en toda su producción ficcional, autobiográfica o autoficcional, y su compromiso ciudadano.

\subsubsection{Producción}

Maïssa Bey encarna la corriente de autobiografías escritas por mujeres tan características de la literatura argelina actual. Empezó a publicar en la Argelia atormentada de los años 90, siendo ahora una figura importante de las letras argelinas, reconocida tanto en Argelia como en Francia².

Publica libros en lengua francesa desde 1996: $A u$ commencement était la mer (1996); A contre-silence (1998); Cette fille-là (2001); Entendez-vous dans les montagnes (2002); Journal intime et politique, Algérie 40 ans après, con Mohamed Kacimi, Boualem Sansal, Nourredine Saadi y Leïla Sebbar (2003); Les Belles étrangères, Treize écrivains algériens (2003); L'ombre d'un homme qui marche au soleil (2004); Sous le jasmin la nuit (2004); Surtout ne te retourne pas (2005); Bleu blanc vert (2006); Pierre sang Papier ou cendre (2008); L'une et l'autre (2009); Puisque mon cœur est mort (2010).

Evoca en esos libros el pasado dramático de Argelia (la guerra y la desaparición de su padre), retrata a las mujeres argelinas oprimidas, reconoce la figura tutelar de Albert Camus; denuncia la guerra de los integristas, o la catástrofe del terremoto de 2003, en Argel. Podemos decir que todos los textos de Maïssa Bey están atravesados por el mismo amor y por la misma pasión hacia Argelia que los textos de Camus, escritos cincuenta años atrás.

Maïssa Bey ha participado también en varios libros colectivos (de no ficción) dedicados a la ciudad de Argel, como: Alger et I'Algérois: Guide culturel et pratique, con L. Boukli y R. Tavernier (Maisonneuve et Larose, 2004), o Alger, 1951: un pays dans l'attente, con fotografías de Etienne Sved, y textos de Malek Alloula, Maïssa Bey y Benjamin Stora (Le Bec-en-l'air, 2005).

2 Ha sido invitada, por ejemplo, al Salón de "Las Bellas Extranjeras" en París, en 2003. 


\subsubsection{Bleu, blanc, vert}
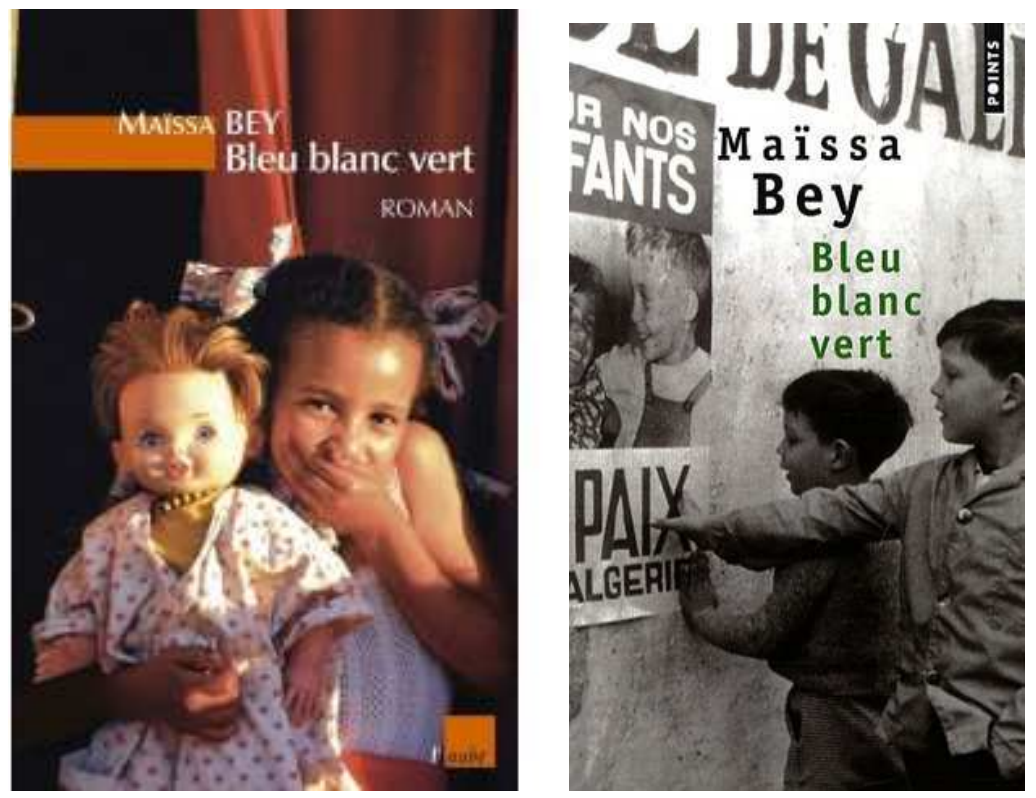

Figura 1. Portadas del libro de Maïssa Bey, Bleu blanc vert (2006).

Bleu blanc vert (2006) pasa revista a la historia de Argelia desde los años 50 hasta 1992. El mismo título del libro, Bleu blanc vert, simboliza por sí solo la mezcla de las banderas, combinando la francesa con su azul, blanco y rojo y la argelina con su color verde. Es también la historia de una chica desde su infancia hasta su vida de casada y de profesional. Alternan el punto de vista de ELLA, la narradora, y de ÉL, el esposo.

El relato de ella empieza tomando Argel como símbolo de la Independencia con el desfile del 5 de julio. Evoca sucesivamente las calles de Argel, el descubrimiento de los pisos abandonados por sus dueños europeos en el mismo edificio donde vive con su madre, la convivencia pacífica con los europeos que se han quedado, las calles con sus nuevos nombres que celebran a los mártires de la lucha, el ambiente fervoroso en la Filmoteca, las tiendas de antigüedades llenas de los muebles recogidos en los pisos de los europeos:

On est entrés dans l'appartement. Il nous a semblé petit, mais très beau. Très propre. Parce que l'appartement était neuf. L'immeuble aussi. Personne n'avait habité là avant nous. L'odeur de peinture était très forte. Ce que j'ai le plus aimé, tout de suite, c'est le balcon. $C^{\prime}$ 'était la première fois que je me trouvais aussi haut. Et puis, entre les deux bâtiments d'en face, on voyait un petit bout de mer qui change de couleur tout le temps (Bey 2006: 35)

Lo mismo que la Alcazaba mora y la ciudad turca permanecieron en la ciudad modelada por los franceses, la ciudad francesa permanece en la Argelia independiente: 


\section{ELLA}

Toute I'histoire d'Alger est écrite dans ses rues. Sur les façades de ses bâtiments. Dans les cours et tourelles qui ornent les petits châteaux en bord de mer du côté de Bologhine, autrefois SaintEugène, dans les allées bordées de mûriers, dans les immeubles de style colonial aux balcons de fer forgé, conçus dans la plus pure inspiration haussmannienne, dans les maisons d'architecture néomauresque sur les hauteurs de la ville, entourées de murs blancs recouverts de grappes de glycines.

Mes promenades ressemblent à une espèce de reconstitution historique. Et je ne me lasse pas de déambuler dans cette ville que j'aime tant, Alger, maintes fois conquise, maintes fois libérée. (Bey 2006: 189-190)

El relato de él se refiere al contraste con el pueblo rural, las casas blancas, el marco de las luchas internas al principio de la Independencia, la huelga estudiantil, el ambiente en las calles, el festival panafricano que hace de Argel la capital de la Revolución internacional (1969), el refugio de todos los revolucionarios, de los perseguidos, la arabización forzada, la escasez de alimentos, el entierro del presidente Bumedienne (1978), la victoria histórica en un partido de fútbol frente a Alemania (1982), las manifestaciones callejeras en octubre de 1988, la operación de limpieza de los edificios, la victoria electoral de los islamistas del FIS (1991), el luto por el asesinato del presidente Boudiaf (1992).

Chaque film est suivi d'un débat au Ciné-pop [...] ce n'est pas un cinéma comme les autres. Chaque semaine un film nouveau est programmé. Pour la culture populaire. Les tickets d'entrée ne sont pas chers. La plupart des spectateurs entrent sans payer [...] A chaque séance, il y a tellement de monde qu'on s'assoit quelquefois dans les allées, sur les escaliers. La salle est trop petite. (Bey 2006: 68)

El relato presenta una voz doble, una masculina, ÉL, y otra femenina, ELLA. En ambos casos tenemos estampas de la ciudad de Argel, pero en Él se da una conciencia política:

ÉL

En Algérie restera aussi, peut-être le souvenir du Festival culturel panafricain [...]. Ses danseurs venus de toute I'Afrique pour remplir de lumière, de couleurs et de musique les rues d'Alger. Alger, capitale de toutes les révolutions, asile et refuge de tous les révolutionnaires. (Bey 2006: 101)

Ainsi dans les rues d'Alger on croise, presque à chaque coin de rue, des hommes et des femmes venus d'ailleurs, de toutes parties du 
monde, pour trouver refuge dans un pays qu'on dit être le phare du Tiers-Monde, ou La Mecque de la Révolution. (Bey 2006: 131)

Comme après une longue hibernation, Alger maintenant ne connaît presque plus de jour sans que ses rues soient envahies par des foules de citoyens bien décidés à se faire entendre, à occuper un terrain à présent accessible. (Bey 2006: 271)

Mientras que en la voz de ella se percibe una constante reivindicación de libertad:

\section{ELLA}

Jour après jour, je me laisse porter par cet appel, et Alger s'offre à moi. Alger la blanche, blanche comme les bougies qu'allument les femmes, là, tout près de moi, sur le tombeau recouvert d'étoffes vertes et soyeuses du saint patron de la ville, Sidi Abderramane, dont la mausolée est source de baraka et, plus loin, un autre jour, sur le catafalque de Sidi M'Hamed, le saint aux deux tombeaux.

Je ne veux pas me laisser prendre au piège de la nostalgie. De cette nostalgie parée des couleurs des mystères orientaux, cultivée par quelques familles désespérément agrippées à leur généalogie, et qui toisent du haut de leur histoire les nouveaux citadins, les villageois qui ont envahi «leur » ville, Algé-riens aujourd'hui élevés au rang d'Algé-rois. [...] Il m'arrive cependant, comme bien d'autres, d'exhumer les souvenirs des promenades sur le front de mer, des odeurs d'anisette, de merguez et de sardines grillées qui rôdaient dans les rues de Bab el Oued et plus loin encore, jusqu'à la pointe est de Fort de I'Eau ou, à l'opposé, de la Madrague, aujourd'hui El Djamila, la tour belle. Ou parfois de prêter l'oreille à ceux qui racontent les marchés hebdomadaires qui se tenaient aux portes de la ville [...]. Certains se souviennent encore aujourd'hui du porteur d'eau et de ses cris au matin, pendant que déjà le pain pétri aux premières lueurs de l'aube commençait à lever dans les cuisines obscures.

Je préfère me perdre dans les labyrinthes de la Casbah, bastion historique, reconnu et célébré de la tradition. Après avoir fait un détour par la place du Cheval, ou Placet El Aoud, sans y voir de cheval, la statue du duc d'Orléans, pointant son épée sur la Casbah, ayant été déboulonnée, j'entre enfin dans la vieille ville, autrefois mystérieuse et envoûtante, accrochée au flanc de la colline, préservant jalousement l'intimité et l'inviolabilité de ses maisons aux murs aveugles, séparées par un dédale de ruelles aussi étroites que malodorantes, lieu propice aux délires enthousiastes et à l'asservissement des fantasmes de multiples voyageurs en mal d'exotisme. La Casbah à présent si délabrée que même ses amoureux les plus fervents s'en détournent et ne rêvent plus que de blocs de béton. (Bey 2006: 186-187) 
También aparece la dificultad de pertenecer a una doble cultura, lo que plantea problemas sexuales, ideológicos y humanos. Se mezclan los problemas individuales, sobre todo los propios de la mujer (búsqueda de trabajo, vida en pareja, parto, soledad), y los colectivos: falta de vivienda, condiciones penosas de trabajo, corrupción general en la Argelia independiente.

Alternan los momentos de euforia personal y colectiva con los momentos de desencanto en la pareja (problemas de convivencia o de maternidad), o por la evolución política del país. Como contrapunto, el descubrimiento feliz de París como antítesis de Argel.

Bleu blanc vert es una doble confesión a partir de una doble enunciación en primera persona que cuenta el itinerario de los dos personajes, desde sus respectivos puntos de vista, sus historias personales. El relato cubre su vida desde 1962 hasta 1992, principio de la rebeldía integrista, con un recorrido dividido en tres décadas: 1962-1972, 1972-1982 y 1982-1992.

Podemos afirmar que Lilas/Leïla representa perfectamente a ese "yo" femenino tan difícil de asumir en una sociedad musulmana que impone un estatuto particular a la mujer, dominada y sometida desde la infancia a unos rígidos códigos morales o sexuales, códigos que la protagonista no admite. La Revolución que trae la Independencia no ha cambiado esa situación, y domina en la mujer la voluntad de transgredir esas normas.

\subsection{Assia Djebar}

\subsubsection{Biografía/Obra}

Djebar se presenta a sí misma como una "mujer árabe que escribe en lengua francesa". Ha sido elegida miembro de la Academia Francesa en 2005. Desde su educación rigurosa en la Argelia colonial ha vivido en ese mundo doble, ha estudiado en París, ha regresado a Argel durante la Independencia para marcharse definitivamente en 1980. Vive actualmente en Estados Unidos. Ha publicado muchos libros sobre ciudades, como Femmes d'Alger dans l'appartement (1980), Loin de Médine (1991), Oran, ville morte (1997) y Nuits de Strasbourg (1997). 


\subsubsection{Nulle part dans la maison de mon père (2007)}
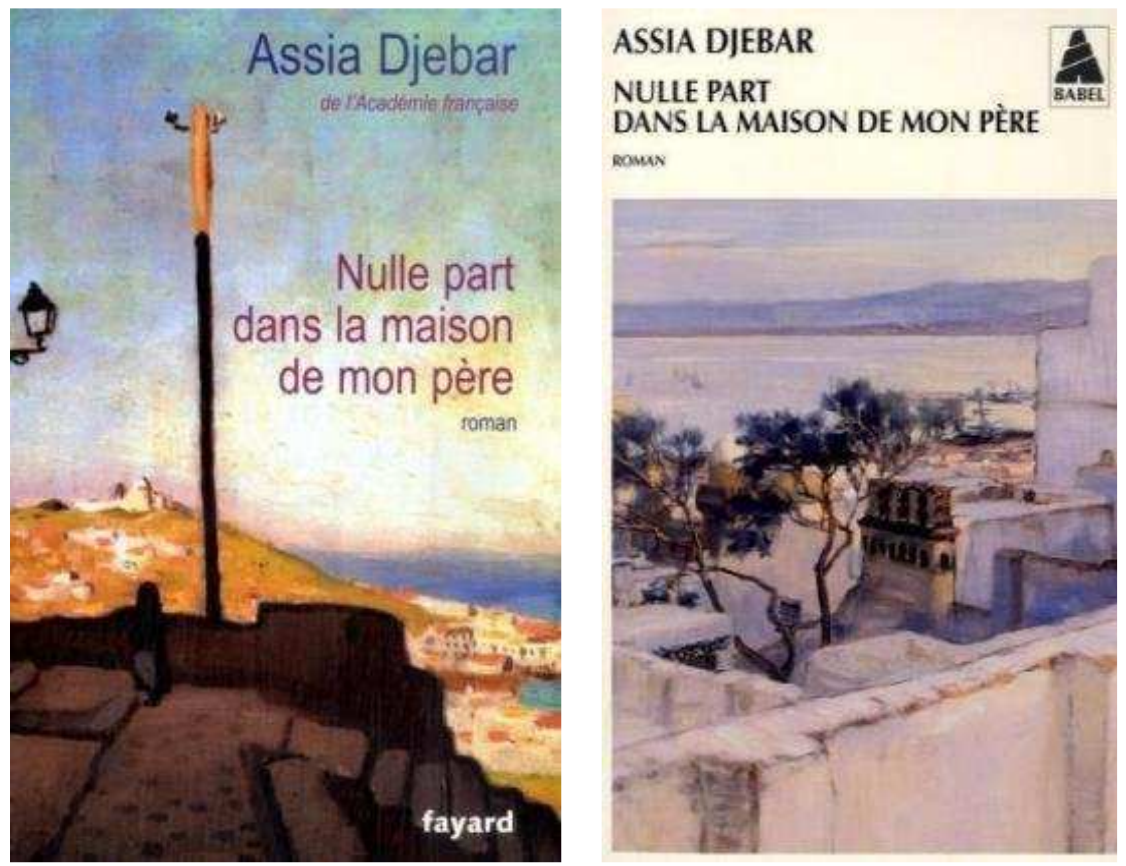

Figura 2. Portadas del libro de Assia Djebar, Nulle part dans la maison de mon père (2007).

Este libro, catalogado como novela, adopta la forma de un relato de vida en primera persona con tres apartados bien delimitados: Éclats d'enfance, Déchirer l'invisible, y Celle qui court jusqu'à la mer. En su estructura narrativa, el relato sigue lógica y cronológicamente el curso de la vida de la protagonista, que es claramente Assia Djebar.

El aspecto novelesco del libro nace de efectos literarios en la disposición del discurso y en sus textos periféricos: un epílogo y un post-prefacio que proponen reflexiones de tipo metaliterario, en los que el autor enjuicia su propia obra. Reivindica la fuerza de "une poussée irrésistible en elle de la mémoire" (Djebar 2007: 380), como portavoz de las mujeres argelinas. En esa labor de des-velar la condición de sus mujeres, la ciudad de Argel desempeña un papel importante: es el cuadro y el motor de esa dialéctica.

De hecho, la llegada a Argel de la protagonista tiene una doble consecuencia: provoca una serie de transgresiones gracias a su nueva vida de estudiante:

Je trouvais aussi plaisir à aller travailler en bibliothèque : I'une, non loin du grand lycée, dans une ruelle proche de la Casbah, avait été aménagée dans un vieux palais turc; je m'y absorbais, dans le silence et la vétusté des lieux, y passant des après-midi entiers, et quand je sortais de là, gorgée de lectures, la tentation me prenait de me hasarder seule dans les proches venelles du cœur de la vieille ville. (Djebar 2007: 302) 
y la metamorfosis de su madre en una mujer occidental libre con el abandono del velo y su conquista de la calle:

Ce terme de «mini-révolution » que j'applique à notre arrivée à Alger, peu avant septembre 1953, se justifie par un détail : ma mère, qui allait fêter ses trente-six ans, se métamorphosa en quelques mois en Occidentale d'une élégance discrète, toujours soignée, bien coiffée : par secrète fierté plus que par vanité, elle conquit son autonomie citadine, passant inaperçue par une allure soudain européenne dans notre quartier où le petit peuple allait et venait autour du grand marché. (Djebar 2007: 298)

En ese entramado se superponen dos mundos antagónicos: el mundo familiar protector y asfixiante y el espacio de la calle atractivo y peligroso; el mundo argelino que es el suyo y el mundo europeo que la atrae con la escuela francesa, su literatura (André Gide o Alain Fournier), la gastronomía, la música, los barrios europeos de la ciudad que descubre, fascinada, con un agudo sentido de la observación. Ve, por primera vez, la sociedad colonial en la que destacan dos ciudades: la ciudad provinciana de Blida y la capital Argel, con sus dos mundos separados. Por una parte, los europeos con sus trajes, sus costumbres, su manera de andar por las calles, su libertad de movimiento, sobre todo las chicas con sus piernas desnudas, y, por otra, los árabes, mucho más pobres, más cohibidos y encerrados en normas estrictas.

Par contre, chaque matin, dans le tramway que je prenais, quel émerveillement! Je m'installais dans la première voiture, si possible loin du conducteur, pour assister au spectacle de l'éveil de la ville, fascinée tantôt par le flux des piétons, tantôt par les places successivement traversées, avec leurs terrasses de cafés à clientèle exclusivement masculine, mais toutes races mêlées [...]. (Djebar 2007: 301)

La ciudad es el marco de esa libertad: paseos con una compañera europea de clase, sesiones de cine, práctica del deporte con el cuerpo en libertad, tardes enteras en la biblioteca, incluso las pastelerías. La ciudad le facilita la transgresión de las leyes prohibitivas de la sociedad islámica:

Je me souviens de ma première année à déambuler sans fin dans Alger, et de cette ivresse qui me saisissait alors : avancer les yeux baissés, rougir d'être prise pour une européenne, car rares encore étaient les adolescentes qui, comme moi, se plaisaient à marcher pour marcher [...] surtout ne pas parler au-dehors de sa langue de cœur, je veux dire sa langue maternelle [...]. (Djebar 2007: 305) 
En ese marco urbano surge la aventura sentimental. La protagonista traspasa los muros familiares para callejear libremente y vivir su amor, lo que provocará la futura ruptura con su novio árabe:

Que me reste-t-il de cette première rencontre? C'était un jour de l'automne ou de I'hiver 1952. La ville d'Alger existe-t-elle déjà pour moi comme lieu de mon premier rendez-vous « amoureux »? Non, je crois être allée ce jour-là à Alger, habitée autant par l'ardente volonté de gagner le match que de «bavarder», me disais-je, pour savoir quel genre d'étudiant serait cet inconnu [...] ressusciter la jeune fille de quinze ans, audacieuse et romanesque, que je devais être. (Djebar 2007: 268)

Je ne me souviens guère de mes propos en descendant aux côtés du jeune inconnu ce boulevard des hauteurs d'Alger. Le silence qui s'installait de temps en temps entre nous, je le laissais s'étaler, occupée que j'étais à m'emplir soudainement les yeux du panorama de l'immense baie, sous le ciel infini d'un bleu intense, si bien que de cette première rencontre, j'ai gardé surtout souvenir de mon émerveillement devant ce paysage. «Alger-la-Sultane ? Oh oui » me dis-je, prise d'une lente ivresse visuelle, grâce à laquelle je surmontais ma gêne auprès de ce compagnon inconnu, si proche de moi. Nous descendions la pente du même pas, avec allant [...] avancer, ainsi «accompagnée » dans cette ville qui m'était étrangère, se révélait une expérience troublante que je savourais. Alors qu'au village n'importe quelle adolescente française pouvait se promener devant tout un chacun, comme on disait « accompagnée », cet adjectif avait pris, pour nous, les musulmanes de l'internat, un double sens, si bien que nous en usions entre nous sur un ton d'amère dérision. Car nous leur enviions ce luxe, aux jeunes européennes ! (Djebar 2007: 270)

Moi seule ou à côté de Tarik, sitôt après avoir quitté le lycée, affronter le bourdonnement continu de la ville chaude, le long des arcades qui préfiguraient le cœur ancestral de la Ville, là où j'aurais aimé aller, accompagnée ou non du fiancé, m'immerger dans le lacis de ruelles étroites, sous les arcades d'un autre siècle! (Djebar 2007: 313)

Désormais étudiante, j'hésite à m'aventurer dans cette Casbah, semblable à quelque Babylone. Ce cœur mystérieux de la capitale, qui sera plus tard le nid d'une tragique et grandiose résistance, me demeura étranger, en cette première année de ma vie étudiante. (Djebar 2007: 317)

La crisis sentimental, con la escena de ruptura -casi la secuencia cinematográfica- y la tentativa de suicidio, coinciden con el inicio de la guerra de Argelia en 1954. Todo ello ocurre en las calles de la ciudad: 
Elle a dévalé les escaliers de pierre jusqu'au boulevard Sadi-Carnot, la jeune fille. Son sac et ses affaires abandonnées gisent à terre. Du haut des marches, le jeune homme l'appelle encore deux fois, peutêtre trois. Courir ...vers quoi ? Hors du vestibule, la jeune fille a-t-elle entendu la rumeur bourdonnante du boulevard, à ses pieds, la mer à I'horizon, dont les bras immenses se tendent vers la fugitive? «Courir ...jusqu'à la mer ! » Elle dévale les trois volées de marches : tantôt la main sur la rampe, tantôt [...]. (Djebar 2007: 357)

Lancée... lancée «Si mon père le sait... je me tue... tue !... » Oui, j’ai voulu m'endormir en travers des rails: être dispersée, poussière devenue, plutôt que masse sanguinolente, enfoncée dans la terre, avec la mer comme premier témoin, mais m'enveloppant, la mer mêlée au ciel, la baie immense pour linceul, ô gloire et mort bienheureuse! (Djebar 2007: 370-371)

De este modo se encuentran y se reúnen dos caminos: el individual de la joven estudiante en su recorrido personal y el colectivo de Argelia en su lucha por la Independencia:

Cette même personne, écrivant la relation plus de cinquante ans après, vient à peine de comprendre que s'est joué là, dans l'éclaboussement de cette matinée d'octobre, un mini-drame à double sens : en ces minutes, derrière le jeune homme plutôt fat, en sus de son rôle de déclencheur, puis de témoin affolé, c'est l'ombre soudain géante du père qui a encombré la baie d'Alger. (Djebar 2007: 383)

Depuis cette aube de 1953, est-ce dans l'une ou l'autre des villes de corsaires d'autrefois, est-ce vraiment dans cette immensité, ce coin d'enfance, là-bas, sur ce rivage où les ruines se dressent plus majestueuses, plus ensoleillées que les demeures des vivants - estce là-bas que je cherche, moi, inlassable, où se trouve la petite, l'obscure maison de mon père. (Djebar 2007: 386)

Solamente en ese momento se da la clave del enigmático título de la novela: Nulle part dans la maison de mon père ('en ningún sitio en casa de mi padre'):

Tu comprends à présent, puisque tu es enfin revenue à cette aube d'octobre 1953, face à l'immense baie d'Alger, un an exactement avant I'insurrection programmée de tout le pays, en cette nuit du 1er novembre 1954 qui allait entraîner la mort d'hommes, de femmes et d'enfants des deux camps, de ceux de ton clan comme de ceux d'en face, alors que toi, tu n'es désormais de nulle part - mais tu ne le sais pas encore... (Djebar 2007: 395) 


\section{Conclusión}

3.1. La ciudad no solamente es un decorado, imprescindible para el desarrollo de la narración al localizarla de modo preciso, sino que participa de y en la diégesis. Hablar de una ciudad en esas novelas no solamente es hablar de lugares (calles, plazas, edificios, jardines) y nombrarlos, sino referirse a lo que sugieren a los seres humanos que viven en ella y cuentan la historia. Hay una cartografía urbana y novelesca. Argel es el marco de la nueva vida de las dos mujeres, ahora independientes como su tierra, escenario de su vida amorosa, por fin libre de códigos asfixiantes. Argel es también el marco de su ascensión social (con el trabajo) y de la evolución política del país, desde la ilusión de la independencia hasta el desencanto personal y colectivo simbolizado por el asesinato del presidente Boudiaf en junio de 1992:

Ils savent, ceux et celles qui, dans les rues d'Alger, une fois de plus endeuillée, ont accompagné de leurs pleurs et de leurs cris de révolte le président jusqu'à sa dernière demeure. (Bey 2006: 281)

3.2. Una ciudad vive, cambia, se metamorfosea. Argel es la representación perfecta de la historia colonial, con su parte europea magnífica, dominadora, aplastante por su típica arquitectura parisina - moderna, frente a la Alcazaba y los barrios populares más humildes. El poder colonial ha edificado una ciudad nueva con inmuebles parecidos a los de Haussmann en París, se han creado bulevares elegantes y rampas frente al puerto, diseñados por los mejores arquitectos franceses desde 1865 y hasta los años 60 , y se ha impuesto un modelo europeo.

Es esa realidad tan alejada de su universo autóctono la que descubren las dos escritoras, que terminan por apropiársela. Incluso en el caso de Maïssa Bey, la joven narradora entra en los pisos antiguamente ocupados y poseídos por europeos. Penetra en el misterio de esos espacios nuevos para ella. Existe una geografía real, pero aparece una gran ambigüedad en la visión de una ciudad amputada de una parte de sus habitantes europeos, experiencia algo insólita en la historia contemporánea. Se impone sin embargo la conciencia de pertenecer a una doble cultura, evidente y pronta en Djebar, y más lenta en Bey, que conoce Argel en el momento de la Independencia.

La voz femenina expresa sobre todo un himno a la ciudad de Argel, eco y correspondencia de su propio estado de ánimo. La narradora del libro de Maïssa Bey lo resume perfectamente en sus reflexiones finales sobre el alma de una ciudad: 
Mais qu'est-ce qui fait l'âme d'une ville? Ses constructions, ses monuments, ses vestiges, ou bien ses habitants ? Alger reste, encore et malgré tout, ville de rencontres, de ruptures et de déchirements, de scènes de liesse ou de désespoir. Je ne saurais dire d'où vient cet appel, cette envie d'aller à la rencontre de la ville. Peut-être du sentiment de plus en plus aigu d'une lente détérioration, lente mais irréversible, et le besoin de me raccrocher à l'histoire, de rechercher dans les rues, dans les pierres, et sur le visage des hommes et des femmes, les traces, l'espoir d'une possible résurrection. (Bey 2006: 185-186)

Alger, faiseuse et défaiseuse de rêves, aujourd'hui dominée par le Mémorial du Moudjahid au-dessus du bois des Arcades et par le monument élevé par les Canadiens, Riadh el Feth, conçu pour marquer à jamais le règne du président Chadli. Alger que nul ne peut évoquer sans parler de sa baie - la plus belle du monde - des virées à la pêcherie, des balades au Jardin d'Essai, des trottoirs remplis d'étudiants de la rue d'Isly, de la rue Michelet, à présent rues Ben M'hidi et Didouche. (Bey 2006: 189)

Alger, parfois impudique, jamais vraiment soumise, et qui garde en elle l'empreinte de ces multiples déchirements, reste encore aujourd'hui indocile, indomptable. (Bey 2006: 190)

Maïssa Bey y Assia Djebar ofrecen un discurso muy sensible y sensual sobre, en y de la ciudad. Más que un discurso femenino es un discurso sexuado, o sea que nace y sale del cuerpo de la mujer. No hay en las dos escritoras ninguna visión apocalíptica de Argel; tampoco idealización. La ciudad no es una utopía, es una realidad muy compleja $y$, en esa perspectiva, el espacio urbano es el campo de los cambios, de las tensiones y de la metamorfosis de la sociedad argelina. 


\section{Bibliografía}

BEY, Maïssa (2006): Bleu blanc vert. Paris: L'Aube.

BOUCHENTOUF-SIAGH, Zohra (2006): Dzayer, Alger, ville portée, rêvée, imaginée. Alger: Casbah éditions.

BOUDJEDRA, Rachid (1991): Le désordre des choses. Paris: Denoêl.

CALVINO, Italo (1996): Les villes invisibles. Paris: Seuil, coll. Points 273.

CAMUS, Albert (1954): "Petit guide pour des villes sans passé", en L'Eté. Paris: Gallimard.

CHIKHI, Beida; y DOUAIRE-BANNY, Anne (2012): Villes, vies, visions: Les villes, propriétés de l'écrivain. Espaces littéraires. Paris: L'Harmattan.

DJAOUT, Tahar (1995): Le Dernier Été de la raison. Paris: Seuil.

DJEBAR, Assia (2007): Nulle part dans la maison de mon père. Paris: Fayard.

DODI, Carla Aklexia (2010): Villes invisibles de la Méditerranée. Paris: L'Harmattan.

MONGIN, Olivier (2005): La condition urbaine. La ville à l'heure de la mondialisation. Paris: Seuil.

SIBLOT, Paul (1992): "La ville d'Alger dans quelques constructions de l'imaginaire français", en Regards croisés, pp. 40-60. La Ville de I'Autre. Montpellier: Éditions Espaces 34.

VIRCONDELET, Alain (1982): Alger, l'amour. Paris: Presses de la Renaissance. 